\title{
“INDIOS" DE LOS OASIS, “INDIOS” DE LA PUNA. PROCESOS MIGRATORIOS Y REARTICULACIONES IDENTITARIAS EN ATACAMA (SUSQUES, SIGLOS XVIII-XIX)
}

\author{
“INDIANS” OF THE OASIS, “INDIANS” OF THE PUNA. MIGRATORY \\ PROCESSES AND THE REFORMULATION OF IDENTITIES IN ATACAMA \\ (SUSQUES, XVIII-XIX CENTURIES)
}

Cecilia Sanhueza Tohá ${ }^{1}$

\begin{abstract}
Desde una perspectiva dinámica de los procesos sociales de construcción de identidades colectivas, se sistematiza y analiza la información de los archivos parroquiales de San Pedro de Atacama (siglos XVIII-XIX) respecto a las poblaciones indígenas de la región de Susques, Puna de Atacama. A través del estudio de las adscripciones tributarias y sociales asignadas a estas poblaciones, se elabora una propuesta respecto a los posibles procesos de reformulación identitaria experimentados por las poblaciones de tierras bajas y tierras altas de Atacama.
\end{abstract}

Palabras claves: Puna de Atacama, Susques, identidades sociales.

From a dynamic perspective of the processes of collective social identity construction, we systematize and analyze the information arising from ecclesiastical archives of San Pedro de Atacama with regard to the indigenous populations of Susques, Puna de Atacama (XVIII-XIX centuries). Through the study of social and tributary affiliation assigned to these populations, this paper attempts to develop a proposition about possible identity reconstruction processes experienced by the lowland and highland peoples of Atacama.

Key words: Puna de Atacama, Susques, social identities.

Nuestro propósito aquí es plantear una discusión respecto a los posibles procesos identitarios vividos por las poblaciones indígenas de la región de Susques, Puna de Atacama, entre mediados del siglo XVIII e inicios del XX. Abordaremos el problema por lo menos desde dos perspectivas. Por una parte, desde las adscripciones o pertenencias sociopolíticas que los dispositivos estatales (coloniales y republicanos) les adjudicaron, y por otra, desde los procesos y prácticas sociales de producción de identidades que surgieron desde la propia experiencia de estas colectividades.

En efecto, partimos del supuesto de que los procesos identitarios no sólo son consecuencia de la relación entre grupos distintos, sino que además están en gran medida condicionados por las relaciones de poder que entre ellos se establecen. Es decir, es desde quienes ejercen el poder en un momento o período dado desde donde se estructuran los marcos referenciales a partir de los cuales se desarrollan nuevas identidades y nuevos sujetos sociales. Sin embargo, si bien los discursos y las prácticas políticas lideran o al menos contextualizan los procesos de construcción de identidades, éstos no son determinados unilateralmente. Se trata, por el contrario, de realidades sociales dialógica y dialécticamente construidas (Abercrombie 1991). Desde esta perspectiva discutiremos los antecedentes disponibles respecto a las pertenencias sociales o de identidad de los habitantes de Susques, región que correspondió hasta los inicios del siglo XX a la jurisdicción de San Pedro de Atacama o Atacama la Alta. Propondremos, además, una aproximación metodológica que, desde los registros eclesiásticos, contribuya al estudio de poblaciones andinas "periféricas" desde la perspectiva de sus posibles sentidos de pertenencia social, de sus cambios y de sus rearticulaciones en el tiempo.

\footnotetext{
Universidad Católica del Norte, Instituto de Investigaciones Arqueológicas y Museo, San Pedro de Atacama, Chile. msanhueza@ucn.cl
} 


\section{El Espacio Puneño, Territorialidades y Dependencias Administrativas}

Un aspecto recurrente en la documentación histórica colonial y republicana es la percepción y representación de la Puna de Atacama como un espacio paradigmático de lo inhabitable, improductivo y marginal, categorías que la configuraron históricamente como un territorio de "frontera" (Sanhueza 2001).

No obstante eso, desde mediados del siglo XVIII el corregimiento de Atacama extendió su jurisdicción hacia esos territorios, puesto que se hacía indispensable un control fiscal (tributario) y doctrinario de la población que se encontraba residiendo allí en forma más o menos permanente $\left(\right.$ Casassas 1974) ${ }^{1}$. Para esos efectos se creó el anexo puneño de Susques, dependiente de la parroquia de San Pedro de Atacama, cuyo amplio territorio parece haber abarcado originalmente desde el oeste o suroeste de Casabindo (anexo parroquial del curato de Humahuaca) hasta los alrededores del enclave minero de Incahuasi, que también fue erigido como anexo de Atacama (Hidalgo 1982a:194) (Figura 1).

Es interesante señalar, sin embargo, que esta región está separada de la cuenca del salar de Atacama por la cordillera de los Andes. Es decir, los nuevos

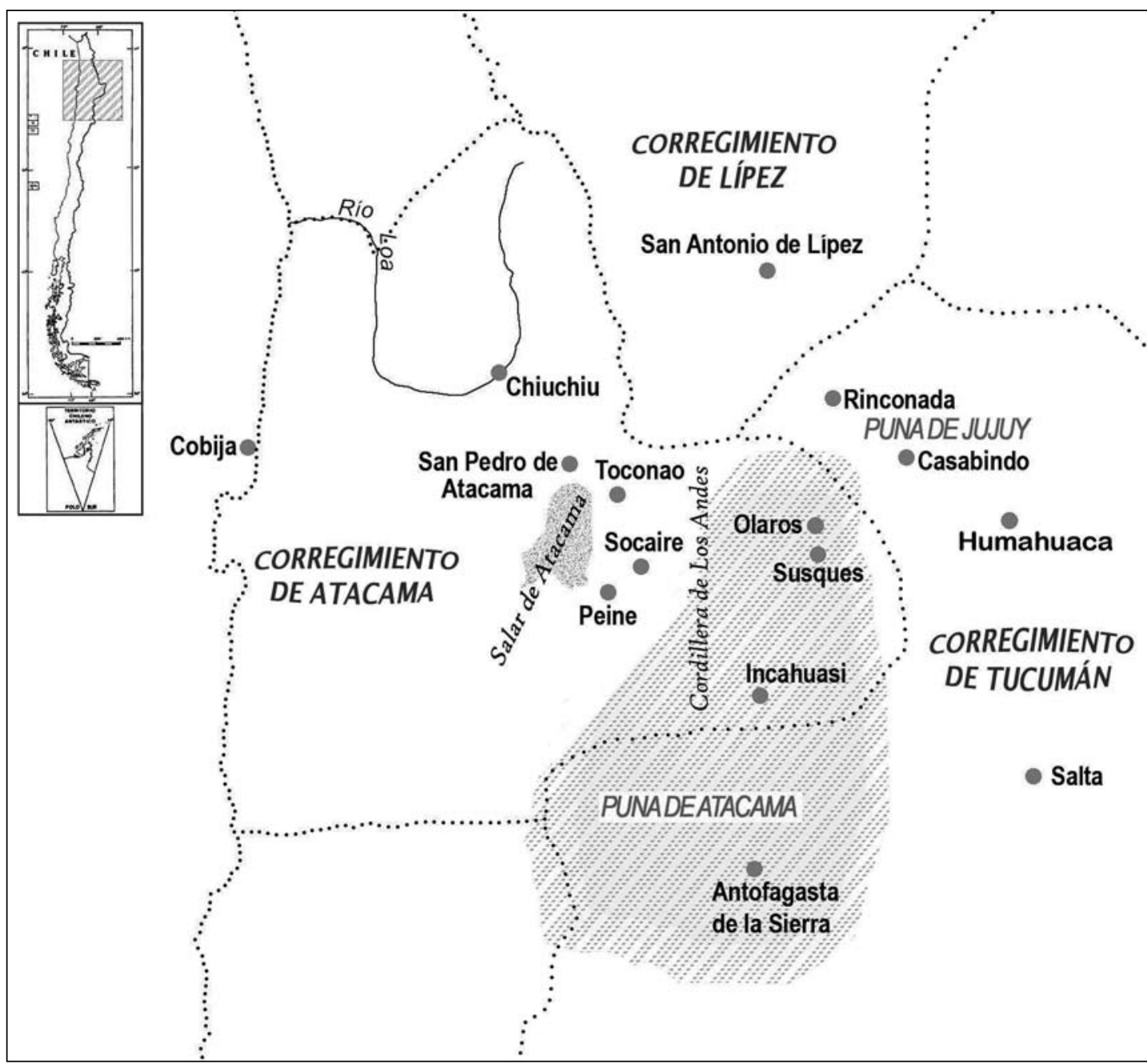

Figura 1. Límites coloniales aproximados del corregimiento de Atacama, establecidos en el siglo XVIII (basados en Hidalgo 1982a). La zona achurada corresponde a la Puna de Atacama.

Approximate colonial limits of the "Corregimiento" of Atacama established in the XVIII century (based on Hidalgo 1982a). The shaded zone corresponds to the Puna of Atacama. 
anexos se encontraban mucho más cercanos a las jurisdicciones doctrinarias del Tucumán que a San Pedro de Atacama. Esto permite suponer que en su incorporación al curato de Atacama debió primar un criterio de carácter social o político en cuanto a los vínculos de su población con los oasis del salar.

Luego de la Independencia, la provincia de Atacama fue incorporada a Bolivia y el anexo de Susques, junto con otros anexos puneños que se habían creado en el intertanto, mantuvo su antigua dependencia doctrinaria y administrativa. El Estado boliviano continuó con el régimen tributario indígena y estas localidades siguieron siendo empadronadas desde la capital de San Pedro de Atacama (Cajías 1975). A partir de 1879, producto de la Guerra del Pacífico, Chile, Bolivia y Argentina intentaron ejercer jurisdicción sobre este gran territorio, hasta que en los inicios del siglo XX gran parte de la Puna de Atacama fue anexada a Argentina (Delgado 2007) (Figura 2).

\section{La "Etnificación" de la Población de la Puna de Atacama desde el Prisma del Siglo XIX}

Exceptuando los registros eclesiásticos y tributarios, es escasa la información disponible sobre las poblaciones de la Puna de Atacama. Sin embargo, a partir de la Guerra del Pacífico la región adquirió un relativo protagonismo por constituir un territorio en disputa entre naciones que aspiraban a mantener, negociar o expandir sus límites territoriales. De allí que durante las últimas décadas del siglo XIX y los inicios del XX el espacio puneño y sus habitantes figuren con mayor frecuencia en la documentación

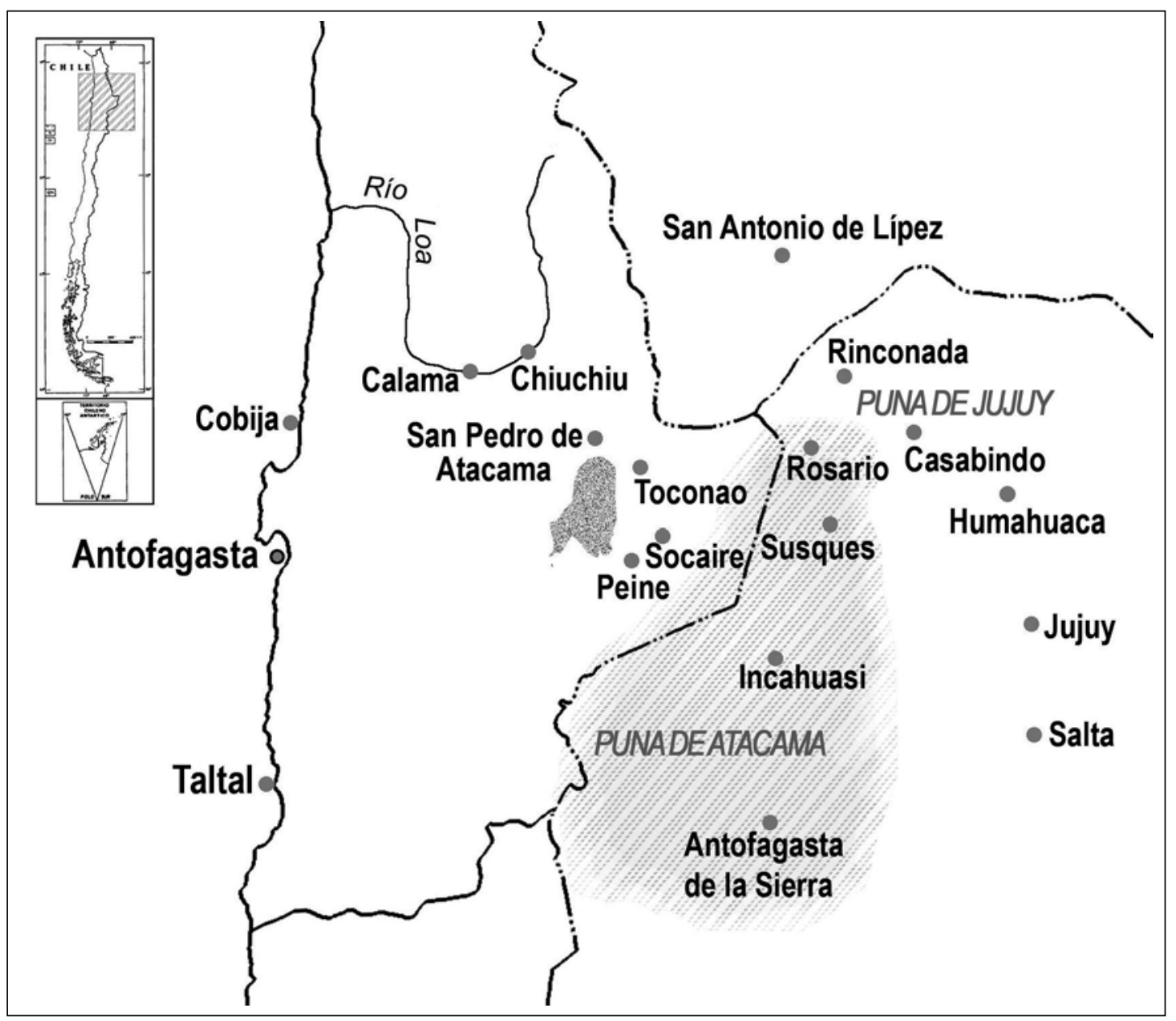

Figura 2. La Puna de Atacama en el contexto de las actuales fronteras nacionales.

The Puna of Atacama in the context of present national borders. 
histórica. Funcionarios, sacerdotes e incluso expedicionarios -científicos o naturalistas- registraron y describieron sus recursos naturales, productivos y sociales, dando origen a un conjunto de textos (informes, diarios de viajes y publicaciones de divulgación) sin precedentes en la región. Es durante este período cuando surgen los primeros estudios que se proponen identificar, definir y describir grandes unidades socioculturales -o más bien raciales, de acuerdo al pensamiento científico de la época- y se divulgan los primeros discursos etnificadores sobre el "indio atacameño" (Bertrand 1885a y b; San Román 1896-1902, 1967; Vaïsse 1894; Vaïsse et al. 1896; Risopatrón 1910 [1903-1904]; Boman 1991 [1908]). La asociación entre "raza", "lengua" y "territorio", indiscutible en la época, lleva a algunos de los principales exponentes de estos estudios a definir la "raza atacameña" a partir de una categoría lingüística, la lengua cunza (en proceso de desaparición), y a circunscribirla geográficamente a las hoyas hidrográficas del río Loa y del salar de Atacama (Vaïsse et al. 1896; San Román 1967:76-77; Risopatrón 1910 [1903-1904]:138-139). Dentro de esa definición (y no obstante que no fuera la única que se postuló en la época), los "indios de la puna", ubicados al otro lado de la cordillera de los Andes, no entraban en la categoría de "atacameños"2.

En ese contexto, es interesante identificar cuáles fueron las pautas de clasificación social y las percepciones sobre los habitantes de la puna que los categorizaron como una población "racial", social y culturalmente distinta a la de las tierras más bajas de Atacama. Por ejemplo, y en particular la población de la entonces subdelegación chilena de Susques, fue considerada como perteneciente a la "raza quechua" (Vaïsse 1892:183). Esta identificación no era del todo arbitraria, según los paradigmas contemporáneos, puesto que los indios de Susques eran principalmente quechua-parlantes (Boman 1991 [1908]:438-439).

Pero no era sólo ese factor el que determinaba las diferencias entre las poblaciones del salar de Atacama y las de la puna. Las fuentes del siglo XIX suelen adjudicar un mayor grado de "civilización" -o una mayor propensión a ella- a los indios de las tierras más bajas de Atacama, mientras que los "indios de la puna" son calificados recurrentemente como más primitivos, extremadamente pobres, aislados y marginales (Bertrand 1885a y b; San Román 1896-1902; Vaïsse 1894). En efecto, los habitantes de la puna, principalmente ganaderos, fueron considerados por las autoridades bolivianas y luego por las chilenas como "miserables" o "paupérrimos" por las bajas potencialidades agrícolas del medio. Incluso, en el período boliviano se les aplicaron medidas de excepción como la rebaja del monto de su tributo con respecto al de las tierras más bajas de Atacama (Cajías 1975). Años después, el párroco de Atacama atribuía, justamente, "a la general apatía de la raza quechua" el que los habitantes de Susques no hubieran desarrollado una agricultura diversificada como en los oasis atacameños (Vaïsse 1892:183).

Otra categoría de diferenciación radicaba en los patrones de poblamiento y ocupación del espacio. Como señalaba Vaïsse (1894), existía una significativa diferencia en el modo en el que los pobladores ocupaban ambos lados de la cordillera: mientras los "indios del lado occidental" (es decir de las tierras bajas de Atacama) vivían reunidos en "poblaciones", los del lado oriental (aquellos de la puna) vivían "apartados unos de otros", reuniéndose sólo algunas veces al año en sus pueblos. De allí provenía, según el cura, el relativo adelanto de los primeros, mientras que los de la puna, diseminados en sus estancias, estaban aún "en las tinieblas del coloniaje".

De manera que, además de incorporar elementos biológicos y linguiísticos, las categorías de diferenciación atribuidas a las poblaciones de tierras altas y bajas establecían también jerarquías y valoraciones socioculturales y económicas. Diferencias que eran percibidas como realidades ancestrales y permanentes.

No obstante, demostraremos aquí que, al menos en tiempos coloniales, una significativa población de la Puna de Atacama tenía estrechos vínculos sociales y de parentesco con aquella del salar. Para ello es necesario detenerse previamente en algunas consideraciones teóricas y metodológicas.

\section{El Escenario y la Cartografía Social en el Período Colonial}

Desde los inicios del período colonial los registros eclesiásticos fueron el principal suministro de información no sólo para el adoctrinamiento sino también para el empadronamiento de la población. Los libros parroquiales establecían quiénes correspondían a la categoría fiscal de "indios", así como los asentamientos, comunidades o ayllus de origen, de pertenencia o de adscripción social o 
tributaria. De allí que se trate de un tipo de fuente que permite, por una parte, iniciar una discusión respecto a las categorías de pertenencia social, territorial o política asignadas por las instituciones españolas a una población específica, y por otra, identificar ciertas prácticas, procesos y cambios sociales locales.

Inevitablemente debemos partir desde un escenario (mediados del siglo XVIII, cuando Susques es incorporado a la jurisdicción de Atacama) en el que ya se han producido y se están produciendo cambios significativos. Como se ha documentado en otras regiones, ciertos grupos o unidades sociales indígenas que identificamos durante el período colonial no se originaron en tiempos prehispánicos, sino en el proceso de reducciones y en el establecimiento de las jurisdicciones administrativas y eclesiásticas. En ciertos casos, las reorganizaciones territoriales españolas determinaron arbitrariamente las pertenencias o dependencias políticas y sociales de una o varias colectividades (Abercrombie 1991; Wachtel 1997). De allí que, si partimos nuestro análisis desde un período colonial tardío, debemos asumir que los "mapas" sociales que suponemos prehispánicos ya habían sido o estaban siendo redefinidos.

\section{Patrones de Asentamiento: un Modelo de Análisis a Tener en Cuenta}

Los estudios multidisciplinarios de la región de Atacama -entendida tradicionalmente como aquel territorio que abarcaba las hoyas hidrográficas del Loa y del salar de Atacama- han postulado la existencia, desde tiempos prehispánicos, de ciertas prácticas o patrones de poblamiento y ocupación del espacio que permiten integrarla a un área mayor, el Área Circumpuneña. Desde esta mirada más amplia, la puna deja de ser entendida como una región de "frontera" y constituye un espacio que, dotado de recursos forrajeros y faunísticos permanentes, permitía articular y complementar las economías de las regiones circundantes. En un medio de características de extrema aridez, como es el caso de Atacama, la optimización de la explotación de recursos diversificados y dispersos habría configurado la combinación de espacios o núcleos de poblamiento más permanente, generalmente asociados a actividades agrícolas en tierras más bajas, con otros de carácter más estacional o transitorio en tierras altas, dedicados principalmente a prácticas ganaderas. En este contexto se habría ido desarrollando desde tiempos prehispánicos un conjunto de estrategias sociales de ocupación y explotación del espacio, articulado a su vez por una constante movilidad e intercambio interregional (Aldunate et al. 1985; Hidalgo 1978; Núñez y Dillehay 1979).

Esta estructura de asentamiento (núcleoperiferia) pudo haber experimentado un mayor desarrollo o énfasis en el contexto colonial, dados los esfuerzos de la administración hispana por concentrar a la población en tierras bajas. Para el siglo XVII, Martínez (1998:163-169) postula que las poblaciones de Atacama, a nivel de los ayllus o incluso de las unidades domésticas, articularon zonas de poblamiento demográficamente más importantes en los oasis o quebradas de la cuenca del salar, con la ocupación de una serie de otros asentamientos dependientes, de carácter más disperso, de baja concentración demográfica y de ocupación menos permanente ${ }^{3}$. En la actualidad, esta práctica que se ha definido como un patrón de articulación "pueblo-estancias" se reproduce principalmente en las comunidades que continúan desarrollando actividades ganaderas (Aldunate et al. 1985; Folla 1989; Núñez 2000).

La documentación colonial da cuenta, solo en forma muy fragmentaria, de estas prácticas de ocupación y usufructo del espacio puneño. La primera revisita conocida, realizada en 1683, menciona como asentamientos sólo a los ayllus inmediatos a San Pedro de Atacama (Condeduque, Sequitor, Solcor, Soncor, Solor, Coyo y Beter), y en el sector oriente del salar, a Toconao, Camar, Socaire y Peine. Prácticamente no hay alusión a la ocupación de tierras más altas, salvo referencias sobre actividades ganaderas de la población del salar de Atacama en localidades puneñas ubicadas fuera del corregimiento, particularmente en la actual puna jujeña y en Lípez (Hidalgo 1984a; Martínez 1998). Es muy probable que esto se deba a que los primeros empadronadores sólo consideraban y registraban los asentamientos con mayor densidad de población ignorando los restantes (Hidalgo 1984a; Martínez 1998:100-101).

Sin embargo, y a medida que la administración española intentaba consolidar su control político y tributario, la dispersión y la movilidad de los habitantes de Atacama comenzó a convertirse en un problema y a evidenciarse en la documentación. Hacia mediados del siglo XVIII, son elocuentes 
las referencias respecto a la ocupación, al menos temporal, de estancias de la Puna de Atacama (p.ej. Olaros, Susques e incluso Antofagasta de la Sierra que estaba hasta entonces fuera de la jurisdicción ${ }^{4}$ ), donde se alimentaba no sólo ganado camélido, sino también mular, vacuno y ovino. Se señalan también actividades mineras y de caza, especialmente de vicuñas. Estos recursos, en especial las lanas y cueros de vicuña, eran intercambiados en la misma cordillera o comercializados en los valles transandinos de Salta (Hidalgo y Castro 1998; Sanhueza 1991:90, 124). Sin embargo, esta ocupación, que suponemos hasta el momento como estacional o temporal, iría adquiriendo, hacia las postrimerías del siglo XVIII, un carácter de mayor permanencia.

\section{Los Libros Parroquiales Coloniales: Segunda Mitad del S. XVIII e Inicios del XIX}

Desde mediados del siglo XVIII figuran como correspondientes a la capital doctrinaria de San Pedro de Atacama el pueblo homónimo y sus ayllus circundantes. Como anexos del curato se encuentran las localidades de Toconao y Socaire y se registran por primera vez los anexos puneños de Incahuasi y Susques (Casassas 1974). Incahuasi fue un importante asiento minero durante el siglo XVIII (Hidalgo 1982a), mientras que Susques era fundamentalmente un espacio de actividad ganadera (Vaïsse 1894). Este último habría sido creado en 1752 (Casassas 1974) y figura a partir de 1764 en los libros de matrimonios y de defunciones de la parroquia de San Pedro de Atacama ${ }^{5}$.

A través de la revisión de las inscripciones de matrimonios y de defunciones efectuadas en Susques entre 1764 y 1789, es decir en un lapso de 25 años, pudimos constatar que la gran mayoría de los indígenas registrados (aproximadamente un $85 \%$ del total promediando ambas fuentes) figuraban como "naturales", "tributarios" u "originarios" de localidades que no pertenecían a este anexo puneño 6 . De ellos, además, una mayoría ( $74 \%$ en promedio) figuraba como originaria de ayllus o pueblos de la cuenca del salar de Atacama. Es decir, de los ayllus de la capital y de los restantes anexos de Atacama la Alta (Figuras 3 y 4).

$\mathrm{Si}$ recurrimos a un registro tipo de estas inscripciones tenemos, por ejemplo, en 1764, el matrimonio de:

\begin{abstract}
Xavier Carlos, indio, hijo legitimo de Francisco Javier, difunto, y María Josefa, tambien difunta, del ayllo de Solcor en Atacama y residente en este [anexo de Susques], con Ramona Michaela, india, hija legítima de Francisco Martín y de Juana Maria, del pueblo de Toconao y residente en este ... (Matrimonios I, 17631808 , f. 4v. Subrayado nuestro aquí y en siguientes citas).
\end{abstract}

Figuran como testigos de este matrimonio Don Pascual Guacasur, de Toconao, Ignacio Bernabé de Soncor y Juan Andrés Cayo de Chiuchiu, "todos residentes en Susques". Por último, como padrinos están "Don Pedro Pablo y su mujer, Doña Ramona Piñero, caciques de Toconao" (Matrimonios I, 1763-1808, f. 4v).

Es necesario considerar que, en general, la adscripción a una localidad, pueblo o ayllu en estas inscripciones se refiere a los padres de quienes se casan o fallecen. Además, la condición mayoritaria de los contrayentes como "hijos legítimos" manifiesta que sus padres estaban dentro del sistema de empadronamiento oficial.

Como se señala en esta inscripción matrimonial y en la gran mayoría de las realizadas durante este lapso de tiempo (1764-1789), los indígenas registrados son adscritos principalmente a ayllus o pueblos de la cuenca del salar de Atacama y especialmente al pueblo de Toconao. En estos 25 años se realizan 55 matrimonios en Susques que involucran a 103 contrayentes indígenas, seis mestizos y un español. Como se detalla en la Figura 3, un altísimo porcentaje de los indígenas es registrado como proveniente de la zona del salar, correspondiendo un $21 \%$ de ellos a los ayllus de Solcor, Soncor, Sequitor, Condeduque y al anexo de Socaire. Por su parte, un 53\% corresponde al anexo de Toconao. De Atacama la Baja, es decir, del otro curato del corregimiento, figura sólo un $3 \%$ de los contrayentes. Como "forasteros", esto es, que no pertenecen a la jurisdicción de Atacama, se registran 11 personas $(11 \%)$ provenientes principalmente de localidades puneñas de la jurisdicción del Tucumán, como Rinconada, Santa Catalina o el Río de San Juan (Matrimonios I, 1763-1808).

Los registros de defunciones mantienen, aproximadamente, estas proporciones. De 159 indígenas fallecidos en Susques en ese mismo período, 117, es decir un $73 \%$, corresponde a población adscrita 
a la cuenca de Atacama la Alta (45\% al anexo de Toconao y sobre un $29 \%$ a los diferentes ayllus y anexo de Socaire). Algo más de un $7 \%$ corresponde a poblaciones "forasteras" en su mayoría provenientes de localidades puneñas de la jurisdicción del Tucumán (Defunciones I, 1763-1791) (Figura 4).

En ambas fuentes (matrimonios y defunciones) se distingue, sin embargo, un reducido número de población que es considerada como "natural" o "de" Susques, sin otorgarse una pertenencia original de sus padres a otra localidad. Esta adquiere una proporción que sólo bordea el $10 \%$ y el $12 \%$ del total de los registros efectuados, respectivamente (Figuras 3 y 4).

Con respecto a la mayoría de los indígenas registrados en este anexo, a pesar de señalárseles un origen no local, se explicita muchas veces su condición de "residentes" allí, aunque continúen tributando, ellos y sus padres, en sus ayllus o pueblos del Salar de Atacama ${ }^{7}$. En ciertos casos, los registrados como "naturales" del anexo, es decir, nacidos allí, y que a su vez son hijos de padres también nacidos en Susques, se siguen adscribiendo a un origen no local. Al mismo tiempo, se explicitan las diferencias entre aquellos que son nacidos allí y quienes son "residentes" de los últimos años ${ }^{8}$.
En definitiva, se observan diferentes categorías relativas a la condición de los contrayentes según su lugar de origen (el de sus padres o abuelos), de nacimiento o de residencia, no obstante que, aparentemente, sigan tributando sólo en sus localidades de origen. Sin embargo, la adjudicación de estas categorías no es todo lo rigurosa que quisiéramos. En muchos casos se señala a los registrados como "de" un determinado lugar, sin distinguir si se trata de una adscripción por nacimiento, por pertenencia ancestral o por correspondencia tributaria.

A pesar de estas imprecisiones, podemos concluir que en este primer período investigado un altísimo porcentaje de los residentes en Susques es definido como originario de localidades que no pertenecen a ese anexo puneño (aproximadamente un $85 \%$ ) y que en su gran mayoría corresponden a las tierras más bajas de la doctrina de San Pedro de Atacama (74\%). Esta población registrada en Susques tiende a establecer y reproducir alianzas matrimoniales y de parentesco ritual (compadrazgo) entre sí. Es decir, los matrimonios se realizan principalmente entre provenientes de los distintos ayllus o pueblos de Atacama y, en mucho menor medida, entre éstos y "forasteros" provenientes de otras jurisdicciones puneñas. Por su parte, la población designada como

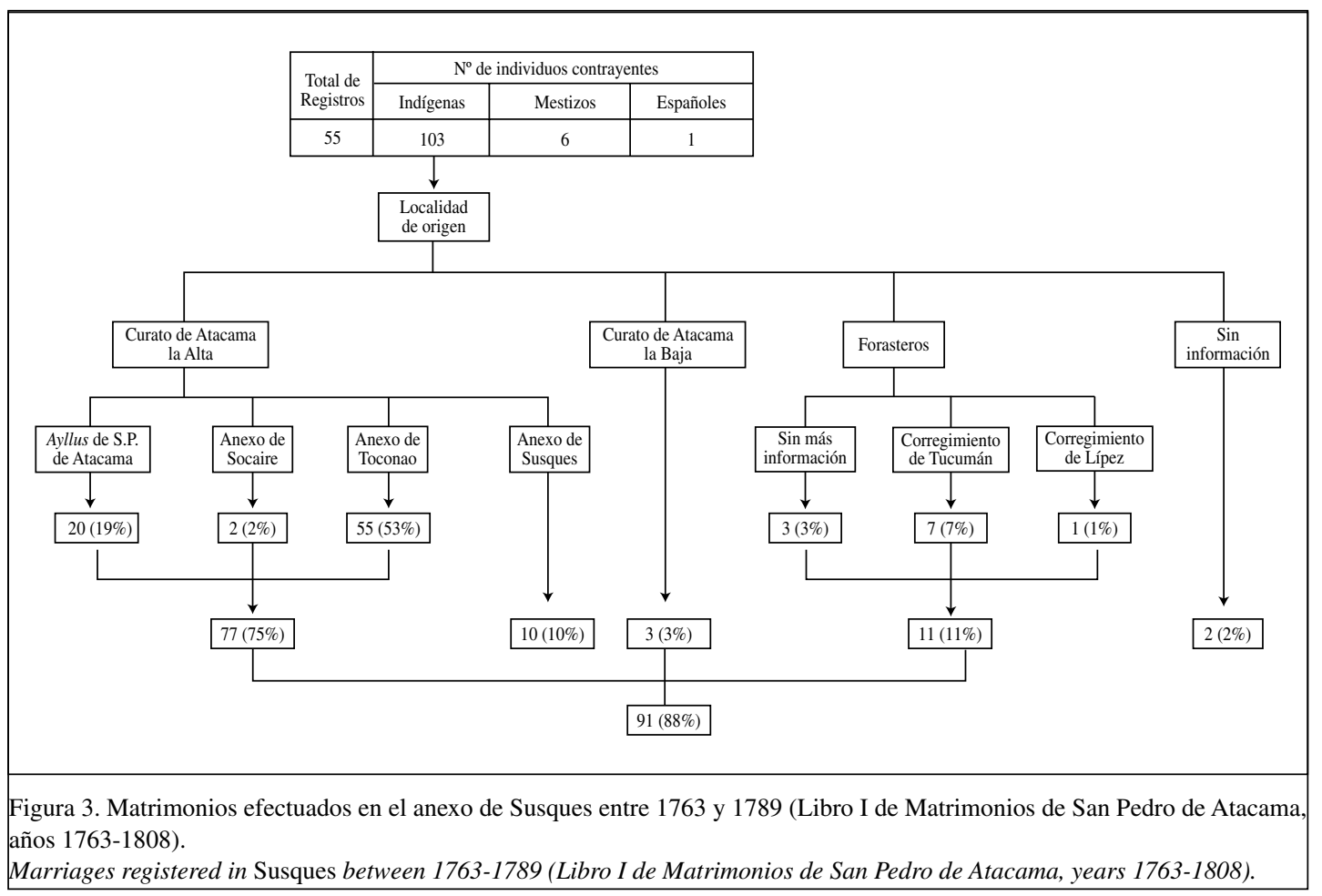




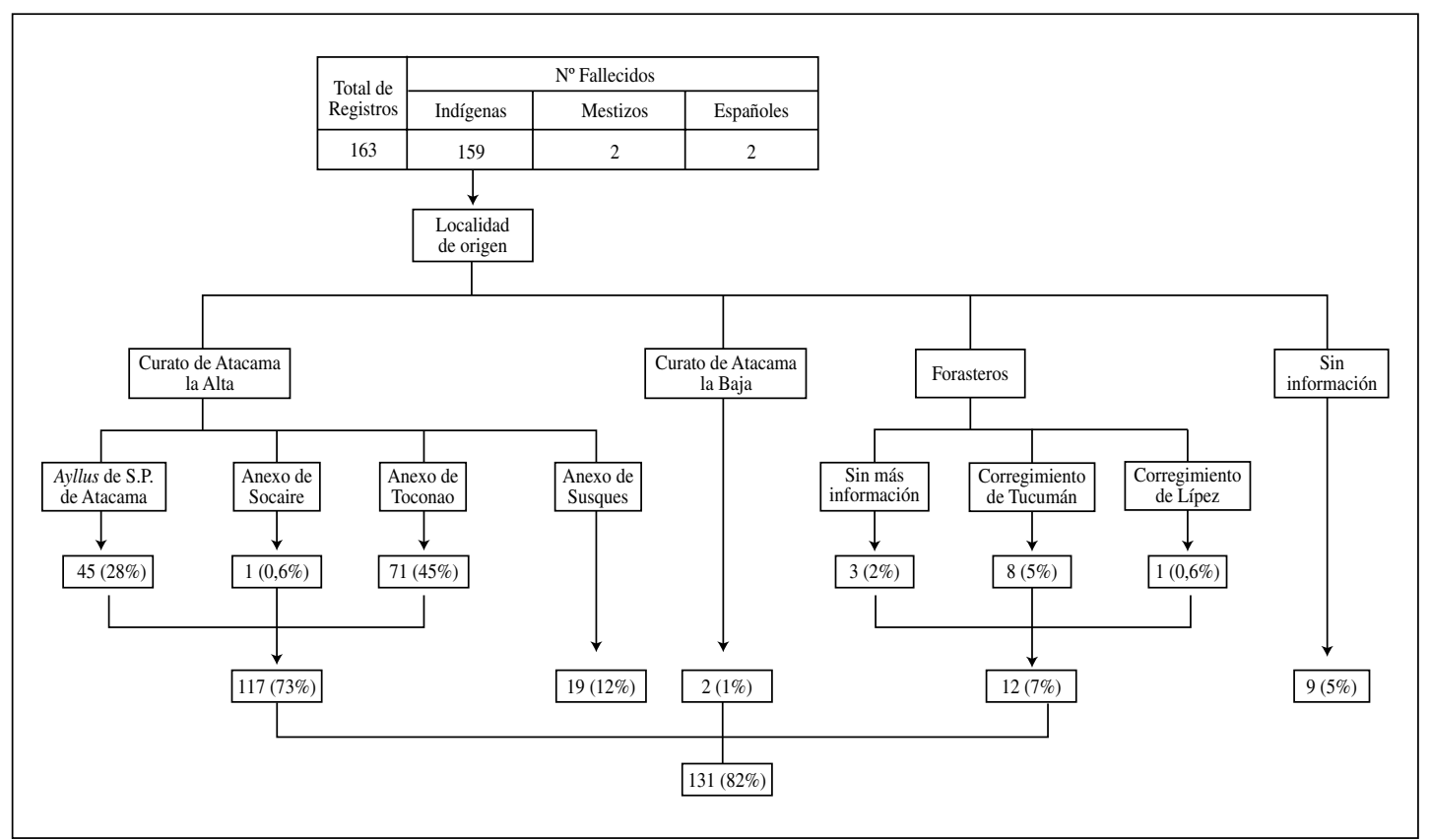

Figura 4. Defunciones registradas en el anexo de Susques entre 1764 y 1789 (Libro de I de Defunciones de San Pedro de Atacama, años 1763-1791).

Deceases registered in Susques between 1764-1789 (Libro de I de Defunciones de San Pedro de Atacama, years 1763-1791).

"de Susques" (en promedio un 11\% de los individuos registrados) establece alianzas matrimoniales entre sí, con gente de los ayllus de Atacama y con "forasteros" (Matrimonios I, 1763-1808).

Lamentablemente, los libros consultados sufren un corte en 1789 y sólo contamos con los registros efectuados a partir de 1808, casi 20 años después 5 . Este segundo libro abarca sólo nueve años y corresponde a la última etapa del período colonial.

La parroquia de San Pedro de Atacama contaba, entonces, con tres anexos en la puna: Susques, Rosario e Incahuasi. Este último presentaba ya una escasa población ${ }^{9}$. El anexo de Rosario, también vinculado a la minería, estaba en un período de mayor auge, registrando 22 matrimonios de origen heterogéneo y que manifestaban cierto nivel de movilidad en la población ${ }^{10}$ (Figura 5).

Sin embargo, en el anexo de Susques, la situación era muy diferente. Prácticamente todos los individuos registrados entre 1808 y 1817 (11 matrimonios, 22 indígenas contrayentes) son definidos como "originarios", "naturales", "hijos de naturales", "de este anejo", "vecinos", "hijos de vecinos", sin mencionarse ningún caso de contrayentes que provinieran, ellos o sus padres, de localidades externas.
Aunque correspondan a un lapso de tiempo muy breve, estos antecedentes, comparados con los del período anterior, evidencian cambios importantes. Pero ise trata de cambios efectivos en cuanto al sentido colectivo de pertenencia social de estas poblaciones, o sólo manifiesta cambios administrativos aplicados desde el aparato fiscal respecto a sus adscripciones tributarias?

$\mathrm{Al}$ respecto, es necesario considerar dos hechos importantes. Por una parte, de acuerdo a nuestra información, a partir de 1787 las poblaciones residentes en el anexo de Susques comienzan a ser empadronadas tributariamente en forma separada de sus antiguas cabeceras o ayllus. Efectivamente, en la revisita practicada al Partido de Atacama en esa fecha aparece, por primera vez, la categoría de "originarios" del anexo de Susques y que son empadronados en la puna (Hidalgo 1978:86). Por otra parte, sabemos que en 1792 se dictaron disposiciones oficiales tendientes a fijar residencia y tributación definitiva en otras jurisdicciones, principalmente en Salta y Tucumán, a aquellos "originarios" de Atacama que se habían ido radicando allí en las últimas generaciones. En esos casos también se optó por cambiar el criterio de adscripción fiscal, 


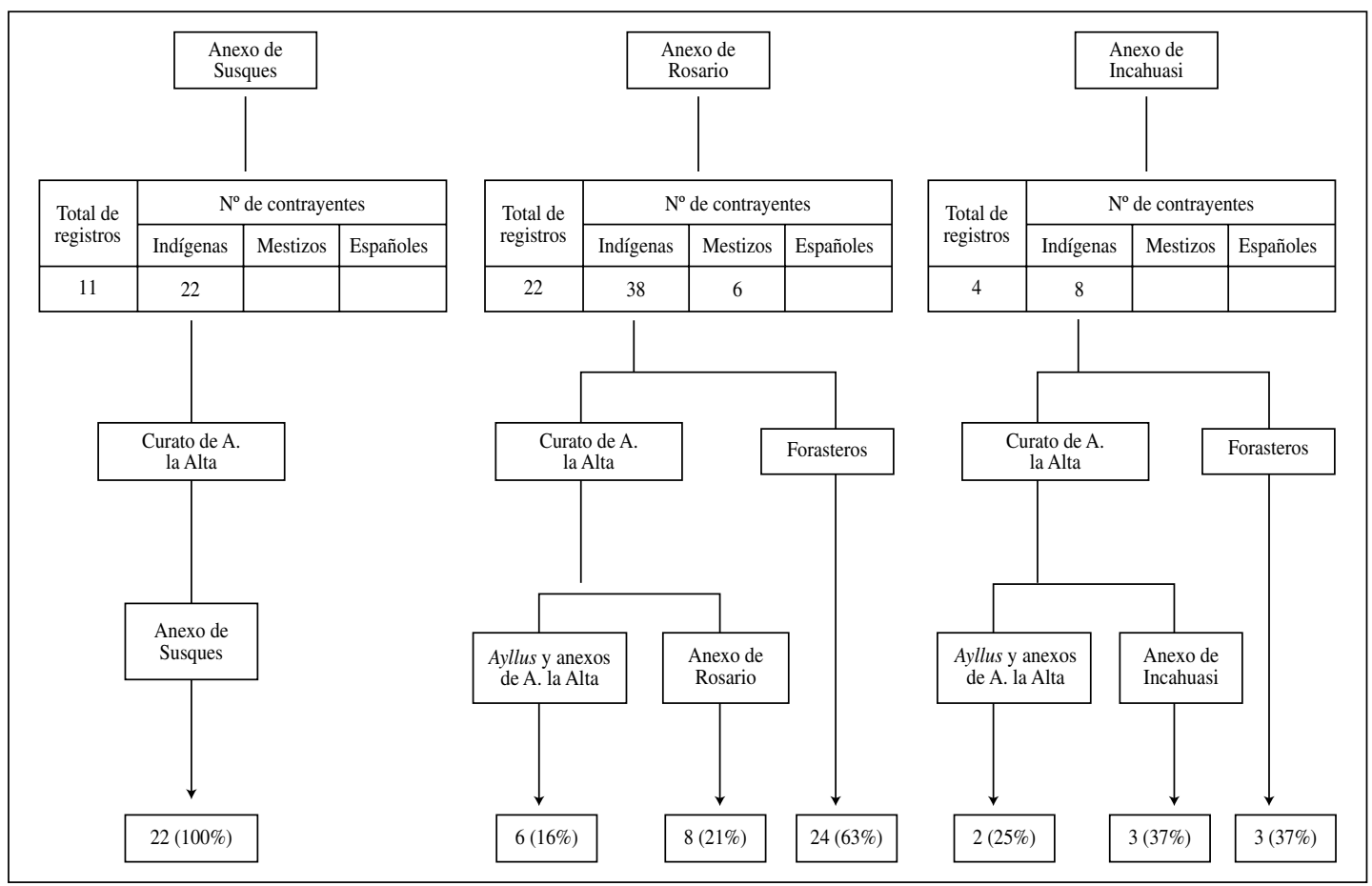

Figura 5. Matrimonios efectuados en los anexos puneños del curato de Atacama la Alta entre 1808 y 1817 (Libro II de Matrimonios de San Pedro de Atacama, años 1808-1817).

Marriages registered in the puna parish annexes of Atacama between 1808 and 1817 (Libro II de Matrimonios de San Pedro de Atacama, years 1808-1817).

puesto que los vínculos tributarios de esas poblaciones eran cada vez más difíciles de sostener para efectos de la recaudación (Hidalgo 1984a). Es decir, estos cambios administrativos habrían correspondido a una readecuación del sistema fiscal ante un proceso migratorio que lo había vuelto inoperante. El caso de Susques, no obstante que pertenecía -y siguió haciéndolo- a la jurisdicción del Partido de Atacama, parece haber obedecido a esos mismos criterios tributarios.

Aunque no nos es posible en este trabajo explicar, dentro de su complejidad histórica, las razones que pudieron impulsar este proceso migratorio, podemos señalar que la presión tributaria colonial debió haber sido un factor de importancia. Así lo señala el estudio efectuado por Hidalgo (1984a) respecto a los desplazamientos de tributarios de Atacama hacia las haciendas y otros centros productivos transandinos con el objeto de acceder a otros ingresos para el pago de las tasas, lo que finalmente habría culminado en una desvinculación definitiva con sus comunidades de origen. Sin embargo, y como el mismo autor lo señala, es necesario considerar también que estas poblaciones estaban reproduciendo antiguas estrategias de movilidad y acceso a recursos distantes. Probablemente, durante un largo proceso de transición, los habitantes de Atacama sustentaron tanto su economía tradicional como aquella enmarcada en el contexto mercantil colonial en una ocupación particularmente dispersa y dinámica del espacio, manteniendo los miembros de los diferentes ayllus sus derechos y obligaciones. Sin embargo, hacia fines del siglo XVIII y en el marco de un control y una presión tributaria más efectiva sobre la población, estas prácticas ancestrales ya no habrían podido mantener su lógica original.

En efecto, y específicamente en el caso de Susques, una lectura diacrónica de los registros efectuados desde 1764 hasta la culminación del período colonial permite advertir cierta secuencia en los cambios producidos en las adscripciones sociales de sus habitantes. Al crearse ese anexo puneño el grueso de su población fue definida como "no originaria". Con el pasar de los años la condición de "naturales" (es decir, nacidos allí) y de individuos o grupos familiares definidos como "residentes" o "de" Susques, fue aumentando paulatinamente. Esto parece haber abarcado un proceso 
complejo, a través del cual -incluso después de dos o tres generaciones- se seguía adscribiendo a contrayentes nacidos en Susques (y cuyos padres eran también ya definidos como "naturales" de ese anexo), a una pertenencia original de sus abuelos en Atacama. Pero hacia los últimos años del período colonial la categoría de "originario" de Susques pasó a ser la de la mayoría de la población local, disminuyendo drásticamente la presencia de individuos o grupos familiares registrados como nacidos u "originarios" de la cuenca del Salar de Atacama. La permanencia relativamente estable de esta población en la puna se puede verificar a través del seguimiento de varios casos individualizables. A modo de ejemplo, en 1764 mencionábamos más arriba, como testigos de matrimonio, al cacique de Toconao y su mujer. Los registros del fallecimiento de dos de sus hijos en los años siguientes (1765 y 1767) y posteriormente del propio ex cacique, en 1785, indican que este grupo familiar se había establecido en Susques (Defunciones I, 1763-1791: fs. $26,30 \mathrm{v}$ y $113 \mathrm{v}$ ).

Una población definida como "originaria" de los oasis se estaba radicando en la puna. Por cierto, el concepto de "radicación" en términos andinos es bastante relativo, puesto que su constante movilidad, no sólo entre las vegas y estancias de altura, sino también hacia localidades más bajas del noroeste argentino, como lo señalan las fuentes coloniales, manifiesta que sus estrategias de acceso a recursos distantes y diversificados seguían operando (Hidalgo 1984a; Pino Manrique citado en Bertrand 1885b:143).

Pero de estos antecedentes se desprende otra discusión. Un alto porcentaje de la población registrada en este anexo en el siglo XVIII era definida inicialmente como "originaria" del "pueblo de Toconao", es decir, de uno de los primeros pueblos fundados por los españoles en Atacama y que parece haber sido una de las más importantes reducciones indígenas de la zona (Hidalgo 1982b). Como tal, pretendía aglutinar y fijar residencia permanente a una población que tradicionalmente estaba dispersa y en constante movilidad entre tierras altas y bajas (Martínez 1998:100-101). Desconocemos si en el período colonial tardío en que nos estamos situando existía ya un verdadero sentido de pertenencia social e identitaria entre los habitantes del pueblo de Toconao. No obstante, si bien no es de extrañar que el propio cacique de Toconao figure en 1764 en Susques ejerciendo como padrino de matrimonio -puesto que evidencia la continuidad de la movilidad trashumántica de las poblaciones "reducidas"-, lo que sí marca un cambio, a nuestro juicio, es que esta autoridad local y su grupo familiar, así como una cantidad considerable de unidades domésticas también adscritas a ese pueblo, se estuvieran estableciendo en forma definitiva en la puna.

El hecho de que el anexo de Susques se instituyera en forma bastante tardía parece deberse a una necesaria readecuación del sistema de registros eclesiásticos y sobre todo del empadronamiento tributario ante un proceso de facto de migración o radicación allí. Pero reiteramos la pregunta de si la continuidad -incluso hasta una tercera generación- de las adscripciones a un ayllu de origen o a un pueblo de reducción ¿se debía a una política administrativa que pretendía perpetuar las dependencias tributarias iniciales, o era una estrategia de las poblaciones atacameñas para mantener sus vínculos de pertenencia social, política y/o ritual con sus comunidades de origen?

Con el paso de los años, sin embargo, el surgimiento de estos nuevos "originarios" de Susques parece estar dando cuenta del inicio de nuevas construcciones identitarias en esa región de la puna de Atacama.

\section{El Escenario y la Cartografía Social en los Tiempos Republicanos}

Una revisión preliminar de los registros parroquiales del período boliviano permite sostener que los lazos originales dejaron de operar o de reproducirse entre las poblaciones del anexo de Susques y las del salar de Atacama, al menos en lo que se refiere a vínculos de pertenencia, a relaciones de parentesco a través de alianzas matrimoniales o a relaciones sociales de compadrazgo.

Para el período boliviano hemos procesado los registros matrimoniales efectuados entre 1836 y 1860 (es decir, un lapso de 24 años). La Parroquia de San Pedro de Atacama comprendía ahora los anejos o viceparroquias puneñas de Rosario, Susques y Antofagasta de la Sierra (Matrimonios III, 18361870) (Figura 6).

El anexo de Rosario presenta una significativa disminución de la población avecindada, manifestando el fin del auge minero, como lo corroboran otras fuentes posteriores (Bertrand 1885a:275; Vaïsse 1894). Sin embargo, el porcentaje de población indígena definida como local ha aumentado 


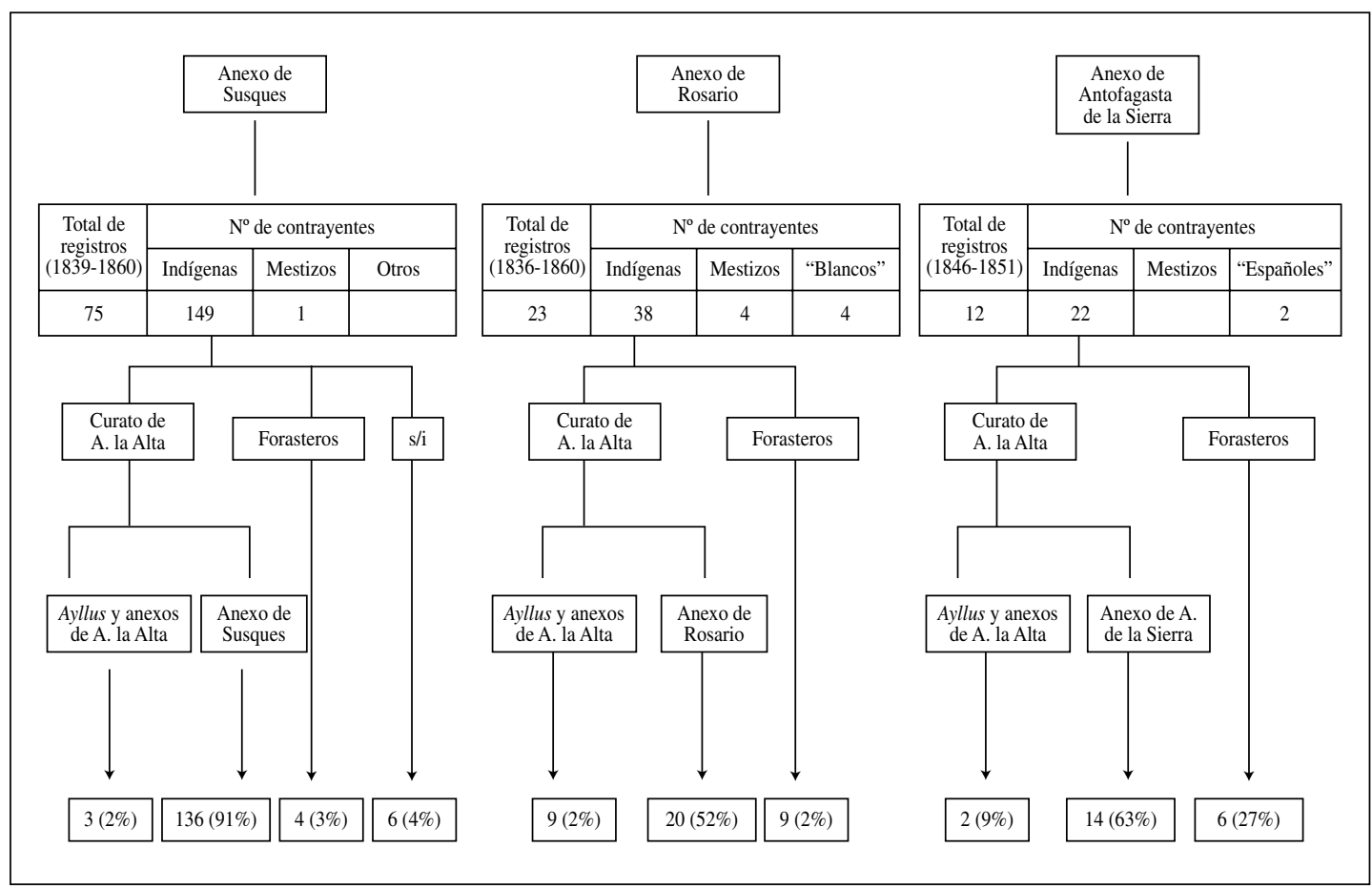

Figura 6. Matrimonios efectuados en los anexos puneños del curato de Atacama la Alta entre 1836-1860 (Libro III de Matrimonios de San Pedro de Atacama, años 1836-1870).

Marriages registered in the puna parish annexes of Atacama la Alta between 1836-1860 (Libro III de Matrimonios de San Pedro de Atacama, years 1836-1870).

notablemente ${ }^{11}$. En Antofagasta de la Sierra, sobre el 60\% de los inscritos figura como "natural" y el resto se distribuye, principalmente, entre originarios de diferentes localidades puneñas ${ }^{12}$.

El anexo de Susques, mucho más importante demográficamente que los anteriores, sigue registrando matrimonios mayoritariamente pertenecientes a esa circunscripción. Entre 1839 y 1860 se realizan 75 matrimonios (149 contrayentes indígenas), de los cuales un $91 \%$ es inscrito como "tributario", "originario", "natural" o "del" anexo, especificándose en muchos casos los nombres de sus localidades de residencia dentro de esta jurisdicción: Susques, Coranzulis, Pastos Chicos, Olaros, Pastos Grandes, El Toro, y una gran cantidad de asentamientos menores (Matrimonios III, 1836-1870).

Los contrayentes considerados como forasteros corresponden, aproximadamente, a un 3\% y comprenden a oriundos de diferentes localidades puneñas argentinas y bolivianas. De los 149 indígenas registrados en este período, sólo un individuo es definido como "originario de Atacama" (los dos restantes corresponden a anexos de la puna). De manera que, como se verificaba para el último período colonial, el proceso migratorio y las alianzas matrimoniales con poblaciones de tierras bajas de Atacama ya no se reeditan, al menos en forma significativa.

\section{Vínculos y Rupturas}

Los mecanismos de control fiscal debieron instituirse en la región puneña para poder fijar "nueva residencia" y someter a un nuevo intento de reducción a una población que, por su distancia de los asentamientos nucleares del corregimiento, presentaba dificultades para el cobro de las tasas. Sin embargo, estos esfuerzos no siempre provocaron los efectos deseados. La "radicación" de población en la región puneña no implicaba su "inmovilidad", ni el abandono de sus patrones de articulación de espacios productivos diversificados y dispersos. El hecho de que una gran mayoría perteneciera ahora al anexo de Susques no significaba la concentración de la población en asentamientos aglutinados o pueblos. Durante el siglo XIX, ciertas localidades como Coranzulis, Susques, Pastos Grandes o Pastos Chicos, 
que figuran entre las más mencionadas, constituían más bien zonas de asentamiento disperso a través de estancias. Las primeras referencias que conocemos respecto al "pueblo" de Susques, propiamente tal, provienen del año 1864 (Bautismos IX, 1862-1896, f. $32 \mathrm{v}$ ). Pero éste, hasta los inicios del siglo XX, no era habitado en forma permanente, sino para las fechas ritual o socialmente significativas (Boman 1991 [1908]; Vaïsse 1894).

Una revisión preliminar del período correspondiente a los años previos y posteriores a la Guerra del Pacífico parece indicar que las relaciones sociales y las alianzas de parentesco de estas poblaciones se desenvuelven principalmente dentro del espacio puneño (punas de Jujuy y de Atacama) (Bautismos VII, VIII y IX, 1849-1896). Pero a la vez, sus estrategias de movilidad se han volcado con un mayor énfasis hacia los territorios transandinos. En 1892, Vaïsse describía a Susques como el segundo distrito más importante de la entonces subdelegación chilena de San Pedro de Atacama, contando con una población de 800 a 1.000 habitantes, dedicados principalmente a la crianza de ganado. Sus otras actividades consistían en intercambiar ganado y textiles por diferentes productos en el sur de Bolivia y en los valles argentinos. Los habitantes de Susques durante este período, sostenía Vaïsse (1892:184), prácticamente no tenían relaciones económicas o comerciales con Atacama, no obstante que ésta continuara siendo su capital administrativa.

\section{La Comunidad de Susques en los Inicios del Siglo XX}

Hacia 1903 contamos con un valioso material registrado por el arqueólogo E. Boman (1991 [1908]) sobre la entonces llamada Comunidad de Susques. Al definir la composición étnica de los "indios" de Susques, Boman enfatiza sus diferencias respecto al resto de los habitantes de la puna. Desde los paradigmas etnológicos de su época, la describe como una "tribu" racialmente "pura", de prácticas estrictamente endogámicas, de una economía autárquica y de una condición social y geográfica extremadamente aislada. Es decir, como una comunidad "estática" que no había sufrido cambio alguno durante los últimos siglos (Boman 1991 [1908]:435, 464).

Según su pormenorizado relato, la mayoría de los habitantes de Susques no vivían en el pueblo, sino que se encontraban en él sólo para las fiestas religiosas o las asambleas de la comunidad. La asamblea y la autoridad local (el "cacique" o "capitán" de Susques) eran respetadas y su convocatoria podía reunir a familias que se hallaban diseminadas en grandes distancias (Boman 1991 [1908]:433-434). Contradictoriamente con lo señalado más arriba, el propio autor describe la capacidad de articulación económica de la producción local con el altiplano boliviano y valles argentinos. La actividad ganadera en las estancias abarcaba un inmenso territorio (de hasta $100 \mathrm{~km}$ de distancia), y se alternaba con el desplazamiento regular a otras regiones para practicar el comercio y el intercambio. De hecho, los productos agrícolas de más alto consumo (coca y maíz) no eran cultivados localmente sino adquiridos afuera a cambio de textiles, ganado y sal. Con la región de Atacama, sin embargo, prácticamente no tenían relaciones comerciales, o éstas eran muy poco frecuentes (Boman 1991 [1908]:433-434, 440-463).

Otro aspecto importante destacado por Boman era la lengua de los habitantes de Susques. Si bien señalaba que todos, al menos los hombres, hablaban el español, el idioma principal de la población era el quechua. Respecto al cunza, sostenía que los susqueños negaban conocerlo, no obstante que empleaban palabras en ese idioma y parecían comprenderlo bien (Boman 1991 [1908]:438-439). Recordemos que, hacia fines del siglo XIX, el párroco de Atacama (y experto en lengua cunza, E. Vaïsse) definía a los habitantes de Susques como de "raza quechua". Este problema, no del todo resuelto hasta el estado actual de nuestra investigación, permite proponer algunas hipótesis. Por una parte, podemos señalar que quienes mayoritariamente iniciaron el poblamiento permanente en la región de Susques eran cunza-parlantes (Hidalgo 1984b:227). Sin embargo, sabemos que en tiempos coloniales la población de Atacama manejaba varias lenguas, entre ellas la aymara y la quechua (Martínez 1998:85-86). Creemos que es posible que el uso del quechua se haya potenciado producto del estrechamiento de los vínculos con las regiones transandinas que, durante el período colonial, vivieron un proceso de "quechuización" o de expansión de esa lengua (Nardi 1962). Probablemente a ello debió sumarse la radicación de poblaciones quechua-parlantes provenientes de otras regiones puneñas y del sur de Bolivia, y de la cual los registros parroquiales podrían no estar dando cuenta en su real magnitud. 
No obstante lo anterior, Boman (1991 [1908]) señala un fuerte vínculo religioso de los habitantes de Susques con la parroquia de Atacama. Era frecuente que éstos acudieran a la iglesia de San Pedro para celebrar bautismos y matrimonios. Sólo una minoría recurría a las entonces parroquias de Casabindo, Cochinoca o San Antonio de los Cobres, situadas mucho más cerca y que no requerían atravesar la cordillera (Boman 1991 [1908]:434-435). Ello a pesar de que, en la época en que Boman visitaba la comunidad de Susques (1903), ésta había dejado de pertenecer a la jurisdicción chilena (Delgado 2007). Cabe entonces preguntarse si estos lazos eran producto de la fuerte influencia que habían ejercido sus curas párrocos, o denotaba, además, algún tipo de relación más profunda entre la población de Susques y los oasis del Salar.

Hay muchos aspectos de la historia de la "comunidad de Susques", tal como se la describe en los inicios del siglo XX, que desconocemos. A medida que hemos desarrollado una mirada diacrónica respecto a sus orígenes, asistimos a un proceso de redefiniciones identitarias articuladas $-\mathrm{y}$ en gran medida provocadas- por las dinámicas de resistencia y adaptación a los poderes y estructuras coloniales y nacionales.

Pero los procesos de construcción de identidad requieren de una memoria histórica, de una articulación entre el pasado y el presente, en la que la profundidad temporal sea una forma de legitimación de la existencia de una colectividad. Nos surge, entonces, la pregunta ¿qué memoria existía entre los susqueños de los inicios del siglo XX respecto a sus orígenes? Afortunadamente Boman, a su manera, también se la planteó:

¿Cuál es el origen de esta tribu? Los indios mismos no saben nada sobre eso. El Capitán Victoriano me aseguraba que la iglesia de Susques databa de hace más de cuatrocientos años; es decir, de antes de la conquista española del Perú y que su casa en el pueblo había sido construida por su padre, hace 60 años (...). Muchos indios se acordaban de sus abuelos, algunos aún de sus bisabuelos, pero ninguno pudo darme detalles sobre el origen o las migraciones posibles de la tribu. Parecían estar convencidos de que sus antepasados habían vivido en Susques desde la creación del mundo (Boman 1991 [1908]:464).

\section{Reflexiones Finales}

Algunas fuentes históricas o académicas de las postrimerías del siglo XIX identificaban a las poblaciones puneñas como correspondientes a una "raza" distinta a aquella de los "indios atacameños". Estas diferenciaciones establecidas externamente podrían, sin embargo, corresponder también con sistemas de diferenciación que efectivamente se habían ido construyendo desde las propias poblaciones indígenas a través de un complejo (aunque relativamente breve) proceso histórico y social.

En ese contexto, el archivo parroquial se nos presenta como una herramienta de gran interés para una aproximación a esos procesos de cambio. Pero es también un "arma de doble filo". Por una parte, contiene o constituye un discurso etnificador y ordenador de los "mapas sociales", estableciendo, a través de pertenencias tributario-administrativas, supuestas pertenencias identitarias. Por otra, nos permite percibir lo que, creemos, son complejos procesos de rearticulación o reformulación identitaria. ¿Pero hasta qué punto se pueden separar ambos factores? ¿Desde dónde se sientan las bases o se establecen los marcos que definen o determinan estos procesos? ¿Se trata, como decíamos inicialmente, de un sistema de identidades dialécticamente construido?

Agradecimientos: Esta investigación fue financiada por los Proyectos FONDECYT No 199053 y $\mathrm{N}^{\circ} 1040290$. Se agradecen muy especialmente las sugerencias, comentarios y aportes de los evaluadores de este artículo. 


\section{Referencias Citadas}

\section{Fuentes Inéditas}

Libro I de Defunciones de San Pedro de Atacama, años 1763 1791.

Libro I de Matrimonios de San Pedro de Atacama, años 17631808.

Libro II de Matrimonios de San Pedro de Atacama, años 1808-1817.

Libro III de Matrimonios de San Pedro de Atacama, años 1836-1870.

Libros VII, VIII y IX de Bautismos de San Pedro de Atacama, años 1849-1896.

\section{Publicadas}

Aldunate, C.; J. Berenguer; V. Castro; L. Cornejo; J.L. Martínez y C. Sinclaire

1985 Cronología y Asentamiento en la Región del Loa Superior. Universidad de Chile, Santiago.

Abercrombie, $\mathrm{T}$.

1991 Articulación doble y etnogénesis. En Reproducción y Transformación de las Sociedades Andinas. Siglos XVIXX, compilado por S. Moreno y F. Salomón, pp. 197-212. Ediciones ABYA-YALA, Quito.

Bertrand, A.

1885a Memoria sobre la exploración a las cordilleras del desierto de Atacama. Anuario Hidrográfico de la Marina de Chile X:4-299.

1885b Memoria sobre las Cordilleras del Desierto de Atacama y Regiones Limítrofes. Imprenta Nacional, Santiago.

Boman, E.

1991 [1908] Antigüedades de la Región Andina de la República Argentina y del Desierto de Atacama. Tomo II, Universidad Nacional de Jujuy.

Cajías, F.

1975 La Provincia de Atacama 1825-1842. Editorial Universo, La Paz.

Casassas, J.M.

1974 Noticias demográficas sobre la región atacameña durante el siglo XVIII. Estudios Atacameños 2:75-92.

Delgado, $F$.

2007 "En virtud de ignorar si pertenecíamos...”. Estrategias de resistencia de los moradores de la Puna de Atacama ante su incorporación a los estados chileno y argentino (18841904). Tiempos de América. Revista de Historia, Cultura y Territorio 14:49-67.

Folla, J.C.

1989 Anthropologie Économique d'une Communauté Paysanne de Désert d'Atacama: Socaire. Memoria para optar al grado de Maître en Sciences, Departamento de Antropología, Universidad de Montreal.

García, S., D. Rolandi y D. Olivera, editores

2000 Puna e Historia. Antofagasta de la Sierra, Catamarca. AINA, Buenos Aires.

Hidalgo, J.

1978 Incidencias de los patrones de poblamiento en el cálculo de la población del Partido de Atacama desde 1752 a 1804. Las revisitas inéditas de 1787-1792 y 1804. Estudios Atacameños 6:53-111.

1982a Fases de la rebelión indígena de 1781 en el Corregimiento de Atacama y esquema de la inestabilidad política que la precede 1749-1781. Chungara 9:192-246. 1982b Fechas coloniales de fundación de Toconao y urbanización de San Pedro de Atacama. Chungara 8:255-264.

1984a Complementariedad ecológica y tributo en Atacama, 1683-1792. Estudios Atacameños 7:422-442.

1984b Descomposición cultural en Atacama en el siglo XVIII: Lengua, escuelas, fugas y complementariedad ecológica. Simposio Culturas Atacameñas: 221-249, $44^{\circ}$ Congreso de Americanistas, Universidad del Norte, Antofagasta.

Hidalgo, J. y N. Castro

1998 Fiscalidad, punición y brujerías. Atacama, 1749-1755. Estudios Atacameños 13:105-135.

Martínez, J.L.

1998 Pueblos del Chañar y del Algarrobo. Los Atacamas en el Siglo XVII. Dibam, Facultad de Filosofía y Humanidades, Universidad de Chile, Santiago.

Nardi, R.

1962 El quichua de Catamarca y La Rioja. Cuadernos del Instituto Nacional de Investigaciones Folklóricas 3:189285.

Núñez, L. y T. Dillehay

1979 Movilidad Giratoria, Armonía Social y Desarrollo en los Andes Meridionales: Patrones de Tráfico e Interacción Económica. Universidad del Norte, Antofagasta.

Núñez, M.K.

2000 Movimientos y Voces en Peine. Tesis para optar al grado de Licenciatura en Antropología. Universidad Academia de Humanismo Cristiano, Santiago.

Rasnake, R.

1989 Autoridad y Poder en los Andes: Los Kuraqkuna de Yura. HISBOL, La Paz.

Risopatrón, L.

1910 [1903-1904] La Línea de Frontera con la República de Bolivia. Sociedad Imprenta y Litografía Universo, Santiago.

Sanhueza, C.

1991 Orígenes y Desarrollo de la Arriería Indígena Colonial en Atacama. Tesis para optar al grado de Licenciado en Historia, Pontificia Universidad Católica de Chile, Santiago.

2001 Las poblaciones de la Puna de Atacama y su relación con los estados nacionales. Una lectura desde el archivo. Revista de Historia Indígena 5:55-82.

San Román, F.

1896-1902 Desierto y Cordilleras de Atacama (3 vols.). Imprenta Nacional, Santiago.

1967 La lengua cunza de los naturales de Atacama. Ancora 3:76-88, Antofagasta.

Vaïsse, E.

1892 Memoria del Ministerio del Interior, presentada al Congreso Nacional en 1892, Intendencia de la República, Tomo III, pp.180-184. Imprenta Nacional, Santiago.

1894 Artículo publicado en el Diario El Industrial, Antofagasta, 21 de junio de 1894.

Vaïsse, E., F. Hoyos y A. Echeverría

1896 Glosario de la Lengua Atacameña. Imprenta Cervantes, Santiago.

Wachtel, N.

1997 Nota sobre el problema de las identidades colectivas en los Andes Meridionales. En Arqueología, Antropología e Historia en los Andes. Homenaje a María Rostworowski, editado por R. Varón y J. Flores, pp. 677-708. IEP, Lima. 


\section{Notas}

1 Hasta entonces el corregimiento estaba organizado en dos doctrinas o curatos. La principal, en términos demográficos y administrativos, era Atacama la Alta, con cabecera en San Pedro de Atacama. Incluía los oasis y ayllus circundantes a la capital y los anexos de Toconao, Socaire y Peine en la cuenca del Salar. Atacama la Baja, con cabeza doctrinaria en San Francisco de Chiuchiu, comprendía los pueblos y asentamientos del curso medio y superior del río Loa, además del anexo y puerto de Cobija (Hidalgo 1978).

2 Una importante excepción a este respecto fue el arqueólogo sueco E. Boman (1991 [1908]), quien postulaba la extensión de la "cultura atacameña" hacia sectores de la Puna de Atacama. Entre ellos, la región de Susques.

3 En un sentido amplio entenderemos por ayllu, al menos desde el siglo XVII, a cada una de las unidades sociales (propias de las sociedades segmentarias) que se estructuraban en base a relaciones de parentesco y relaciones rituales de origen mítico. Cada ayllu se organizaba bajo una autoridad política común y regulaba los derechos de acceso de sus unidades domésticas a recursos agrícolas y ganaderos considerados dentro de su territorio (Rasnake 1989). En el caso atacameño, el territorio nuclear de cada ayllu parece haber correspondido a cada uno de los pequeños oasis homónimos que circundaban al centro administrativo colonial. Sin embargo, y atendiendo a la discontinuidad territorial característica de los habitantes circumpuneños (sensu Martínez 1998), no conocemos con mayor precisión los mecanismos que organizaban el acceso a los recursos dispersos y lejanos ubicados en las tierras altas y cómo se distribuían, en un mismo nicho o espacio productivo, los derechos de explotación entre miembros de ayllus distintos.

4 Si bien en tiempos republicanos Antofagasta de la Sierra era un anexo parroquial de Atacama, en el período colonial parece haber pertenecido administrativa y eclesiásticamente a Catamarca (García et al. 2000).

5 Los libros parroquiales de la doctrina de San Pedro de Atacama correspondientes al siglo XVII están extraviados. Los del siglo XVIII se encuentran incompletos y sólo hemos podido trabajar los años 1763-1789 (Libro I de Matrimonios 17631808; Libro I de Defunciones 1763-1791). Para la última etapa del período colonial pudimos revisar el breve lapso comprendido entre 1808 y 1817 (Libro II de Matrimonios 1808-1817).
6 Los porcentajes y cifras que exponemos aquí son aproximados, puesto que, si bien la mayoría de los registros proporcionan antecedentes para establecer localidades de pertenencia, hay siempre un pequeño porcentaje respecto al cual no se entrega información.

7 Por ejemplo: Registro de Matrimonio de hijo de "indios tributarios del ayllo de Toconao residentes en estas estancias de Susques", con hija de "indios tributarios de Toconao y con la misma residencia en esta de Susques" (Matrimonios I 1763-1791, año 1778 s/f).

8 Por ejemplo: Matrimonio de hijo de "indios del pueblo de Toconao naturales de dicho anejo de Susques", con hija de "indios del dicho pueblo y residentes en dicho Susques" (Matrimonios I, 1763-1791, año 1787, s/f).

9 Una revisión preliminar de los registros del anexo de Incahuasi (que en el libro parroquial mencionado incluye sólo cuatro matrimonios entre 1814 y 1817) manifiesta que este enclave se encontraba en decadencia. La población indígena presenta una relativa heterogeneidad en cuanto a su adscripción, correspondiendo a Atacama la Alta, Antofagasta de la Sierra, Lípez y sólo dos de los contrayentes son considerados como "de" Incahuasi.

10 Un $63 \%$ de los contrayentes indígenas no provenía de ese anexo. Sus lugares de origen eran principalmente localidades puneñas de la jurisdicción del Tucumán (como el curato de La Rinconada), y en menor medida de las jurisdicciones de Chichas y de Lípez (Matrimonios II, 1808-1817).

11 Si bien en el breve período anterior (1808-1817) se habían registrado 22 matrimonios, en estos 24 años se realizan 23 matrimonios, que incluyen 38 "indios", cuatro "mestizos" y cuatro "blancos". De los indígenas, un 52\% figura ahora como "de este anejo". Se registra sólo un individuo de los ayllus de Atacama, y el resto proviene de los otros anexos puneños del curato. Los forasteros provienen principalmente de la puna jujeña y de otras localidades de la Puna de Atacama.

12 De 12 matrimonios efectuados entre 1846 y 1851 en esa localidad, se inscriben 14 "naturales" de Antofagasta, uno "originario" de San Pedro de Atacama, uno de Susques y los restantes seis se distribuyen en localidades de la puna de Atacama, correspondientes ahora a territorio argentino: Fiambalá, Molinos y Belén. 
